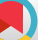

\title{
Bullying and Being Bullied; How Much Can It Increase the Risk of Depression and Anxiety in Students? A Multilevel Fixed-effect Model
} Analysis

\author{
Ebrahim Babaee ${ }^{1}$, Marzieh Nojomi ${ }^{2}$, Mehran Asadi-Aliabadi ${ }^{1}$ and Babak Eshrati ${ }^{1, *}$ \\ ${ }^{1}$ Preventive Medicine \& Public Health Research Center, Psychosocial Health Research Institute, Department of Community and Family Medicine, School of Medicine, Iran \\ University of Medical Sciences, Tehran, Iran \\ ${ }^{2}$ Professor of Community Medicine, Preventive Medicine \& Public Health Research Center, Psychosocial Health Research Institute, Department of Community and Family \\ Medicine, School of Medicine, Iran University of Medical Sciences, Tehran, Iran \\ "Corresponding author: Preventive Medicine \& Public Health Research Center, Psychosocial Health Research Institute, Department of Community and Family Medicine, \\ School of Medicine, Iran University of Medical Sciences, Tehran, Iran. Email: eshrati.b@iums.ac.ir
}

Received 2020 September 26; Revised 2021 March 07; Accepted 2021 March 14.

\begin{abstract}
Background: School violence as a health issue is a global concern. One of the problems that affect the health and well-being of children at school is bullying.

Objectives: In this study, we aimed to examine the association of depression and anxiety with bullying among 6 - 19-year-old students in Iran.

Methods: This study was conducted in Tehran, Iran, in 2020. A multistage cluster sampling method was used, and 54,550 students aged six to 19 years of both sexes, from urban and rural areas, were selected. Standard questionnaires, according to the WHO recommendations, were used for data collection. Involvement in bullying in the past 12 months and anxiety and depression status in both bully and bullied students were investigated by standard questionnaires. To compare the psychiatric problems and violent behavior, the Wald chi-square test was applied. The multilevel fixed-effect model and logistic multivariate regression were used to adjust the multilevel effects and estimate the odds of anxiety and depression in both bully and bullied students. All statistical analyses were performed at a $95 \%$ significance level.

Results: Of the total students, 50.9\% were males, $29.45 \%$ were in the 6 - 10 age group, and $70.55 \%$ in the 11 - 19 age group. There was a significant difference in depression and anxiety between boys and girls in both age groups $(\mathrm{P}<0.001)$. Amongst males, $11.7 \%$ of the students aged $6-10$ and 11\% of the students aged $11-19$ and in females, 7.7\% aged $6-10$ and 10.4\% aged $11-19$ had at least four experiences of bullying to others in the last year. The odds ratios for depression in male bullies were 1.3 and 1.5 in 6 - 10 and 11 - 19 age groups, respectively. The odds ratios for depression in bullied males and females were 4.2 and 3.9 in 6 - 10 and 2.9 and 4.3 in 11 - 19 age groups, respectively. Bulling others increased the odds of anxiety to 1.7 and 1.9 in males and 2.1 and 1.9 in females in 6 - 10 and 11 19 age groups, respectively. In bullied students, the odds of anxiety were estimated at 2.9 and 2.2 in males and 3.4 and 2.2 in female students respectively, in 6 - 10 and 11 - 19 age groups.

Conclusions: There was a significant positive association between psychological disorders (anxiety and depression) and bullying among 6 - 19-year-old students. Victims of bullying were more at risk of depression and anxiety. This health-threatening phenomenon should not be ignored.
\end{abstract}

Keywords: Anxiety, Bullying, Bullied, Depression, Students

\section{Background}

School violence as a health issue has become a global concern in recent years. One of the problems that affect the health and well-being of children at school is bullying. Bullying is defined as aggressive, unjustified, intentional, and persistent behavior, characterized by the power imbalance between victim and aggressor $(1,2)$. Based on various studies, these behavioral disorders are usually observed for the first time in the early years of primary school and peak between the ages of 8 and 15 (3).

Based on the evidence, bullying as a health problem, unfortunately, affects one-third of adolescents in schools worldwide $(4,5)$. This rate in North American schools is $30 \%$ (6). At a national level, bullying in Iranian schools is the biggest challenge, as in other countries (7). Based on a study in Tehran, Iran, in $2014,28,6$, and $34.5 \%$ of the stu- 
dents were victims, bullies, and both bullies and victims, respectively (8). According to another national survey, the prevalence of bullying among Iranian male students at all level grades was $29 \%$, and the bullying victimization rate was $20 \%$. These rates in female students were 25 and $14 \%$, respectively (9).

According to previous studies, boys are more likely to be bullied or bully-victims (10-12). Based on a meta-analysis, bullied students are at least two times more likely than non-bullied males to have psychosomatic problems (13). The results of studies show that students who bullied or were victims of bullying are more susceptible to suicide because of the high level of depression (14), and suicide death is significant among adolescents involved in bullying (15). Students who are victims of bullying also have low academic performance $(16,17)$. A study in the Kingdom of Saudi Arabia showed that students who were bullied were $20 \%$ less likely to perform well academically (4).

\section{Objectives}

Because of less detailed studies in terms of bullying within the schools of both sexes, in this study, we aimed to examine the association of depression and anxiety with bullying victimization and bullying perpetration among 6 -19-year-old students in Iran.

\section{Methods}

This study was conducted in Tehran, Iran, in 2020 as per the ethical guidelines approved by the Research Council of National Institutes for Medical Research Development (NIMAD). In this survey, we used data from four stages of the CASPIAN (childhood \& adolescence surveillance and prevention of adult non-communicable disease) survey. The CASPIAN study is conducted by the Ministry of Health to assess the health status of children and adolescents (students) and the risk factors of non-communicable diseases between the ages of six and 19 years.

The eligibility criteria were being Iranian, not having any particular diseases, and school attendance at the time of sampling. All students and their parents completed informed consent forms for participating in the study. In this study, a multistage cluster sampling method was applied. The study population was students aged six to 19 years in 31 provinces. The primary sampling unit in all studies were the provinces of Iran that were randomly selected (18). In each city, students were randomly selected for the study, based on their educational level. After the final sample size estimation, approximately 54,550 students were included in the analysis. Students were from both sexes, urban and rural areas, and all school levels. The ratio of males to females was considered equal.

For collecting demographic, general health, psychiatric problems, and violent behavior data, the Persian versions of standard questionnaires, according to WHOGlobal School-Based Student Health Survey (GSHS) were used (19). These questionnaires were used to measure the number of aggressive behaviors, bullying, and victimization of students during the last 12 months (9). The validity and reliability of these questionnaires were evaluated by psychiatric and psychology experts after translation. After each pilot study, questions with any difficulty in comprehension were modified. The questionnaire's internal reliability was assessed and approved (Cronbach's reliability coefficient $>0.7)(20,21)$. Data collecting was carried out by health experts in the provinces and city health centers. The experts consisting of healthcare professionals and nurses had passed necessary training for the completion of questionnaires (22). The training process was conducted in a cascading manner. Some staff were initially trained at the Ministry of Health level and were referred to lower and executive levels for training other staff. Staff retraining was also conducted during the CASPIAN study as needed. To measure the engagement in bullying activities, we asked the participants how many times they were involved in bullying others or the number of times they were victimized in the recent year during school hours. The participants were categorized into three groups: (1) never, (2) 1 - 3 times, and (3) equal to or more than four times based on the number of engagements in bullying activities as the one who either bullied or was bullied, based on their roles.

The Persian version of the GSHS questionnaire was also used to screen depression, and anxiety as psychiatric distresses on bullied students and those who were not bullied and in bullies and those who were not bullies. This part of the questionnaire, which has been used in the other previous CASPIAN study, consisted of seven questions that assessed the psychological distress of students in the last six and 12 months (23).

We applied the multilevel fixed-effect model for analyzing the data. The four survey stages (CASPIAN) were considered as level 1 factors, and age groups were considered as level 2 factors.

We expressed quantitative variables as means (95\% CI) and categorized variables as percentages (95\% CI). To compare psychiatric problems and violent behavior according to sex and age groups, a Wald chi-square test was applied. We reported all the results acquired based on responses in 6 - 10 and 11 - 19 age groups. In addition to information on those who bullied others and the others who were bullied, we adjusted the analysis based on general health variables. This variable describes some of the health indicators of stu- 
dents, such as physical conditions and so on.

The multilevel fixed-effect model and logistic multivariate regression were applied to adjust the multilevel effects and estimate the odds of anxiety and depression in bullies and bullied students. Estimated odds ratios were reported based on age and sex groups. All assumptions underlying this model were examined. The significant degree of the age-cohort period effect was examined. The collinearity among the covariates was examined using the Spearman correlation test, and no significant collinearity was detected. Given that we used the pairwise analysis method in this project, we did not take any action on missing data. Data were cleaned, coded, and entered into the software. All statistical analyses were performed at a 95\% significance level using Stata software version 14 (Stata Corp, College Station, TX, USA).

\section{Results}

In this research, 54,550 students were included in the analysis. Of the total students, 50.9\% $(n=27,778)$ were males. The mean age of male and female students was relatively equal [12.57 (95\% CI: 12.53 - 12.61) and 12.59 (95\% CI: 12.55 - 12.63), respectively]. About $22.8 \%$ of the participants were residents in rural areas and $77.2 \%$ in urban areas. Of the included subjects, 29.45 and $70.55 \%$ were in the age groups of 6 - 10 and 11 - 19 years, respectively. The mean age of the students in the age groups of $6-10$ and 11 - 19 years was 8.49 (95\% CI: 8.47 - 8.51) and 14.29 (95\% CI: 14.26 - 14.31), respectively. The 6 - 10 age group mostly included elementary students, and the 11-19 age group included middle and high school students. Of the total included students, 44.17\% were in elementary schools, and 55.83\% were in secondary and high schools.

The demographical, behavioral, and psychiatric characteristics of the students are shown in Table 1. Based on the results, there was a significant difference in the prevalence of depression and anxiety between boys and girls in both age groups $(\mathrm{P}<0.001)$. In both age groups, girls were more anxious and depressed. Besides, $11.7 \%$ of male students aged $6-10$ and $11 \%$ of male students aged 11 - 19 along with $7.7 \%$ of female students aged $6-10$ and $10.4 \%$ of female students aged 11 - 19 had experiences of perpetration to bully others at least four times in the last year. The difference between age groups in terms of the times of participation in bullying was significant in female students $(\mathrm{P}<$ $0.001)$ but not significant in male students $(P=0.37)$. Also, the results showed that in males, $4.7 \%$ of the students aged $6-10$ and $4.8 \%$ aged $11-19$, and in females, 4.1\% aged $6-10$ and $3.8 \%$ aged 11 - 19 were victims of bullying at least four times in the last year.
The findings of this study indicated that students in the 11 - 19 age group of both sexes were more likely to carry a cold weapon (knife, etc.) to school. Furthermore, $1.2 \%$ of boys and $1.1 \%$ of girls in the 11 - 19 age group had a history of carrying cold weapons to school six or more times in the recent month. Consideration of the involved levels in the study showed no age-period-cohort and study-period effect detectable $(\mathrm{P}<0.001)$.

The estimated adjusted odds ratios for depression and anxiety using multilevel logistic regression analysis are provided in Table 2. Based on the multivariate model, the odds of depression increased only in 11 - 19 age groups significantly by increasing the times of bullying others in males. But, in other age and sex groups, increased bullying of others had a non-significantly decreasing effect on the chance of depression. The estimated odds ratios for depression in males were 1.3 (95\% CI: $0.9-1.8$ ) and 1.5 (95\% CI: $1.2-1.8$ ) in the $6-10$ and $11-19$ age groups, respectively, with a history of being bullied at least four times during the past year.

According to our findings, the odds of depression increased significantly in both sexes and age groups by increasing the times of being bullied. In other words, the estimated odds ratios for depression in males were 4.2 (95\% CI: 3.1 - 5.7) in the 6 - 10 age group and 2.9 (95\% CI: $2.3-3.6)$ in the 11 - 19 age group with a history of being bullied at least four times by others. In bullied female students, the estimated odds ratios for depression were 3.9 (95\% CI: 2.8 - 5.7) in the 6 - 10 age group and 4.3 (95\% CI: $3.3-5.4)$ in the 11 - 19 age group. In terms of the anxiety status of students, both bullying of others and being bullied significantly increased the odds of anxiety in both sexes and age groups. In this regard, perpetration on at least four occasions of bullying others increased the odds of anxiety to 1.7 (95\% CI: 1.3 - 2.2) and 1.9 (95\% CI: 1.7 - 2.3) in males and 2.1 (95\% CI: 1.5 2.7) and 1.9 (95\% CI:1.6 - 2.3) in females in 6 - 10 and 11 - 19 age groups, respectively. In bullied students, the odds of anxiety were estimated at 2.9 (95\% CI: 2.1 - 3.9) and 2.2 (95\% CI: 1.8 - 2.7) in males and 3.4 (95\% CI: $2.4-4.8$ ) and 2.2 (95\% CI: $1.8-2.8$ ) in female students respectively in $6-10$ and $11-19$ age groups.

\section{Discussion}

The present study showed how much participation in bullying activities occurs, and how much it can increase the risk of anxiety and depression in students. The results of our study showed that bullying others and being bullied can be significantly associated with depression and anxiety in students of all education levels. According to our findings and confirmation from the results of some previous studies (24-26), bullying others and being the victim of 


\begin{tabular}{|c|c|c|c|c|c|c|c|c|}
\hline \multirow{2}{*}{ Variables } & \multicolumn{4}{|c|}{ Male } & \multicolumn{4}{|c|}{ Female } \\
\hline & $6-10, y$ & $11-19, y$ & Total $^{\text {b }}$ & $\mathbf{P}$ & $6-10, y$ & $11-19, y$ & Total $^{\text {b }}$ & $\mathbf{P}$ \\
\hline \multicolumn{9}{|l|}{ Depression } \\
\hline Yes & $592(13.8)$ & $2558(29.2)$ & & & $613(18.6)$ & $2533(29.9)$ & & \\
\hline No & $3212(86.2)$ & $6215(70.8)$ & 12577 & 0.001 & $3127(81.4)$ & $5890(70.1)$ & 12163 & 0.001 \\
\hline \multicolumn{9}{|l|}{ Anxiety } \\
\hline Yes & $868(17.6)$ & $3346(31.1)$ & & & $921(25.2)$ & $3546(31)$ & & \\
\hline No & $3676(82.4)$ & $7674(68.9)$ & 15567 & 0.001 & $3414(74.8)$ & $7119(69)$ & 14999 & 0.001 \\
\hline \multicolumn{9}{|l|}{ Valueless feeling } \\
\hline Yes & $613(14.8)$ & $2766(23.1)$ & & & $652(16.7)$ & $2952(28.4)$ & & \\
\hline No & 3914 (85.2) & $8167(72.9)$ & 15469 & 0.001 & $3722(83.3)$ & $7686(71.6)$ & 15012 & 0.001 \\
\hline \multicolumn{9}{|l|}{ General health } \\
\hline Excellent & $1926(38.8)$ & $4218(37.4)$ & & & $1957(41.1)$ & 4039 (35.6) & & \\
\hline Good & $1966(44.6)$ & $4688(39)$ & & & $1820(41.6)$ & $\begin{array}{c}4524 \\
(40.9)\end{array}$ & & \\
\hline Moderate & $705(15.7)$ & $2388(20.5)$ & & & $638(17.1)$ & $2383(21)$ & & \\
\hline Bad & $36(0.9)$ & $289(3.1)$ & 16216 & 0.001 & $17(0.2)$ & $244(2.5)$ & 15622 & 0.001 \\
\hline \multicolumn{9}{|c|}{ Bulling to others, recent year } \\
\hline Never & $2911(59.4)$ & $7138(57.2)$ & & & $3062(66.5)$ & $7278(60.7)$ & & \\
\hline $1-3$ times & $1367(28.9)$ & $3718(31.8)$ & & & $1047(25.8)$ & $3174(28.9)$ & & \\
\hline$\geq 4$ times & $380(11.7)$ & $1045(11)$ & 16559 & 0.37 & $335(7.7)$ & $1074(10.4)$ & 15975 & 0.001 \\
\hline \multicolumn{9}{|c|}{ Being bullied, recent year } \\
\hline Never & $3390(71.3)$ & $8890(72.8)$ & & & $3406(75.8)$ & $8621(74.7)$ & & \\
\hline $1-3$ times & $1003(24)$ & $2525(22.4)$ & & & $857(20.1)$ & $2463(21.5)$ & & \\
\hline$\geq 4$ times & $275(4.7)$ & $535(4.8)$ & 16618 & 0.58 & $194(4.1)$ & $494(3.8)$ & 16035 & 0.59 \\
\hline \multicolumn{9}{|c|}{ Carrying cold weapon, recent month } \\
\hline Never & $4462(96.7)$ & $11201(94.7)$ & & & $4305(97)$ & $11017(95.3)$ & & \\
\hline 1 time & $96(1.6)$ & $265(2.3)$ & & & $72(1.3)$ & $202(1.8)$ & & \\
\hline 2 - 3 times & $47(0.9)$ & $182(1.2)$ & & & $36(0.9)$ & $153(1.7)$ & & \\
\hline $4-5$ times & $7(0.1)$ & $60(0.6)$ & & & $9(0.2)$ & $16(0.1)$ & & \\
\hline 6 times or more & $26(0.7)$ & $157(1.2)$ & 16503 & 0.046 & $20(0.6)$ & $114(1.1)$ & 15944 & 0.031 \\
\hline
\end{tabular}

${ }^{a}$ Values are express as No. (\%) unless otherwise indicated.

${ }^{\mathrm{b}}$ The sum of subgroups may be less than the total due to missing data.

bullying at least four times are associated with a significant increase in the risk of depression and anxiety. However, the increased risk of depression in some groups was not in line with the increase in bullying frequency to others.

Some previous studies have also shown a negative correlation between bullying perpetration of others and depression (27). Besides, the risk of depression in bullied girls and boys in both age groups was nearly equal. Based on our study, in victimized students, it seems that the risk of depression is higher than in bullies in both sex and both 6
-10 and $11-19$ age groups.

When we examined the association between bullying and anxiety, our results showed that bullying significantly increased the risk of the occurrence of anxiety compared to depression in both sex and age groups in bully and bullied students. Also, in both sexes, the risk of anxiety in bullied students was higher in the 6 - 10 age group than in the 11-19 age group. Some studies declare that bullying is more prevalent in elementary school in both sexes, and then the prevalence decreases during junior high school and con- 


\begin{tabular}{|c|c|c|c|c|c|c|c|c|c|c|c|c|}
\hline \multirow{3}{*}{ Variables } & \multicolumn{6}{|c|}{ Male } & \multicolumn{6}{|c|}{ Female } \\
\hline & \multicolumn{3}{|c|}{$6-10, y$} & \multicolumn{3}{|c|}{$11-19, y$} & \multicolumn{3}{|c|}{$6-10, y$} & \multicolumn{3}{|c|}{$11-19, y$} \\
\hline & Depress No.(\%) & OR 95\% CI & $\mathbf{P}$ & Depress No.(\%) & OR 95\% CI & $\mathbf{P}$ & Depress No.(\%) & OR 95\% CI & $\mathbf{P}$ & Depress No.(\%) & OR 95\% CI & $\mathbf{P}$ \\
\hline \multicolumn{13}{|l|}{$\begin{array}{l}\text { Bulling to others, } \\
\text { recent } 12 \text { months }\end{array}$} \\
\hline Never & $303(12.5)$ & Ref. & & $1425(26.4)$ & Ref. & & $399(14.9)$ & Ref. & & $1560(27.2)$ & Ref. & \\
\hline $1-3$ times & $219(19.7)$ & $1.5(1.2-1.8)$ & 0.001 & $879(32.5)$ & $1.3(1.2-1.5)$ & 0.001 & $178(20.4)$ & $1.2(0.9-1.5)$ & 0.05 & $807(35.4)$ & $1.5(1.3-1.7)$ & 0.001 \\
\hline$\geq 4$ times & $75(24.5)$ & $1.3(0.9-1.8)$ & 0.1 & $273(38)$ & $1.5(1.2-1.8)$ & 0.001 & $51(19.2)$ & $0.8(0.6-0.2)$ & 0.34 & $213(35.6)$ & $1.2(0.9-1.5)$ & 0.07 \\
\hline \multicolumn{13}{|l|}{$\begin{array}{l}\text { Being bullied, recent } \\
12 \text { months }\end{array}$} \\
\hline Never & $369(13.1)$ & Ref. & & $1768(26.5)$ & Ref. & & $436(14.9)$ & Ref. & & $1750(26.8)$ & Ref. & \\
\hline $1-3$ times & $133(16.8)$ & $1.2(0.9-1.5)$ & 0.17 & $602(34)$ & $1.2(1.1-1.3)$ & 0.003 & $123(17.5)$ & $1.2(0.9-1.5)$ & 0.1 & $609(35.6)$ & $1.3(1.2-1.5)$ & 0.001 \\
\hline$\geq 4$ times & $95(38.5)$ & $4.2(3.1-5.7)$ & 0.001 & $218(51.9)$ & $2.9(2.3-3.6)$ & 0.001 & $68(38.2)$ & $3.9(2.8-5.7)$ & 0.001 & $230(61.3)$ & $4.3(3.3-5.4)$ & 0.001 \\
\hline \multirow[t]{2}{*}{ General health } & - & $1.7(1.5-1.9)$ & 0.001 & - & $1.7(1.6-1.9)$ & 0.001 & - & $1.8(1.6-2.1)$ & 0.001 & - & $1.8(1.7-1.9)$ & 0.001 \\
\hline & Anxious No. (\%) & OR 95\% CI & $\mathbf{P}$ & Anxious No. (\%) & OR 95\% CI & $\mathbf{P}$ & Anxious No. (\%) & OR 95\% CI & $\mathbf{P}$ & Anxious No.(\%) & OR 95\% CI & $\mathbf{P}$ \\
\hline \multicolumn{13}{|l|}{$\begin{array}{l}\text { Bulling to others, } \\
\text { recent } 12 \text { months }\end{array}$} \\
\hline Never & $458(16)$ & Ref. & & $1845(27.6)$ & Ref. & & $571(18.7)$ & Ref. & & $2168(30.9)$ & Ref. & \\
\hline 1.3 times & $269(20)$ & $1.1(0.8-1.2)$ & 0.8 & $1102(31.6)$ & $1.1(0.9-1.2)$ & 0.1 & $217(20.8)$ & $0.8(0.6-0.9)$ & 0.02 & $1064(35.8)$ & $1.9(1.1-1.3)$ & 0.001 \\
\hline$\geq 4$ times & $144(39.5)$ & $1.7(1.3-2.2)$ & 0.001 & $438(47.7)$ & $1.9(1.7-2.3)$ & 0.001 & $145(45)$ & $2.1(1.5-2.7)$ & 0.001 & $390(44.5)$ & $1.9(1.6-2.3)$ & 0.001 \\
\hline \multicolumn{13}{|l|}{$\begin{array}{l}\text { Being bullied, recent } \\
12 \text { months }\end{array}$} \\
\hline Never & $531(15.9)$ & Ref. & & $2261(27.1)$ & Ref. & & $626(18.5)$ & Ref. & & $2463(29.9)$ & Ref. & \\
\hline 1.3 times & $248(25.1)$ & $1.9(1.6-2.3)$ & 0.001 & $892(38.6)$ & $1.5(1.4-1.7)$ & 0.001 & $221(26.2)$ & $1.6(1.3-1.9)$ & 0.001 & $927(41.4)$ & $1.5(1.4-1.7)$ & 0.001 \\
\hline$\geq 4$ times & $9(32.7)$ & $2.9(2.1-3.9)$ & 0.001 & $238(47.8)$ & $2.2(1.8-2.7)$ & 0.001 & $82(42.1)$ & $3.4(2.4-4.8)$ & 0.001 & $235(53.2)$ & $2.2(1.8-2.8)$ & 0.001 \\
\hline General health & . & $1.9(1.8-2.2)$ & 0.001 & - & $1.5(1.5-1.6)$ & 0.001 & . & $1.9(1.8-2.2)$ & 0.001 & . & $1.6(1.5-1.7)$ & 0.001 \\
\hline
\end{tabular}

tinues to decrease into high school (28).

In this study, we found that the prevalence of bullying victimization was not very different between school levels, but bullying others was relatively more prevalent in junior high school and high school students. Finally, victims of bullying were more at risk of depression and anxiety. It also should be stated that boys were more involved in bullying and victimization, almost in all levels of education.

In this ongoing study, we had strengths and some potential weaknesses. Our study sample was representative of the student population for the following reasons. First, the method in which participants were selected confirms that they were representative of their age groups. Second, nearly all schools in the country were involved in the study. Third, a large number of selected students were involved in the research, and the withdrawal rate was low. Some limitations of this study are as follows. Children who did not study in schools for different reasons were not enrolled in this study, and for this reason, we may not be able to extend the results of the study to these children because of differences in some individual characteristics. We also did not examine some of the variables affecting the psychological status, such as the socioeconomic status of students. These could affect the results of the study.

\subsection{Conclusion}

This study indicated a significant positive association between psychological disorders (anxiety and depression) and bullying among 6 - 19-year-old students. Along with the prevalence of bullying others and bully victimization based on sex and age groups, we indicated how many participation in bullying activities and being the victims of bullying increases the risk of anxiety and depression in students.

This study determined that the effect of bullying on anxiety was higher than that of depression, and the impact of victimization was more prominent. Due to the numerous complications of bullying, this phenomenon should not be ignored, and its causes must be rooted. There is an urgent need to merge violence prevention policies in health programs to deal with bullying in schools. Like in some countries (29), screening programs should be designed and generally implemented to assess the behavioral problems of students, such as bullying. Also, effective interventions should be implemented to control bullying in schools.

Further studies should be conducted to investigate why, how, and where bullying occurs among students, and teachers and parents should also get involved in these studies. Results from this study will provide helpful information to conduct successful programs to prevent and in- 
tervene with bullying.

\section{Acknowledgments}

The research reported in this publication was supported by the Elite Researcher Grant Committee under award number 977384 from the National Institutes for Medical Research Development (NIMAD), Tehran, Iran. We also thank the Family Health Administration of the Iranian Ministry of Health and Caspian Studies administrators.

\section{Footnotes}

Authors' Contribution: Study concept and design, all authors; Analysis and interpretation of data, Ebrahim Babaee and Babak Ehrati; Drafting of the manuscript, Marziyeh Nojomi; Critical revision of the manuscript for important intellectual content, Mehran Asadi-Aliabadi; Statistical analysis, Ebrahim Babaee.

Conflict of Interests: All authors report no conflict of interest.

Funding/Support: The research reported in this publication was supported by the Elite Researcher Grant Committee under award number 977384 from the National Institutes for Medical Research Development (NIMAD), Tehran, Iran.

\section{References}

1. Chester KL, Callaghan M, Cosma A, Donnelly P, Craig W, Walsh S, et al. Cross-national time trends in bullying victimization in 33 countries among children aged 11, 13 and 15 from 2002 to 2010. Eur J Public Health. 2015;25 Suppl 2:61-4. doi: 10.1093/eurpub/ckv029. [PubMed: 25805790].

2. Diaz-Aguado Jalon MJ, Martinez Arias R, Martin Babarro J. Bullying among adolescents in Spain. Prevalence, participants' roles, and characteristics attributable to victimization by victims and aggressors. Rev de Educ. 2013;362:348-79. doi: 10.4438/1988-592x-re-2011-362-164.

3. Scott TM, Nelson CM, Liaupsin CJ. Effective instruction: The forgotten component in preventing school violence. Educ Treat Children. 2001;24(3):309-22.

4. AlBuhairan F, Abou Abbas O, El Sayed D, Badri M, Alshahri S, de Vries $\mathrm{N}$. The relationship of bullying and physical violence to mental health and academic performance: A cross-sectional study among adolescents in Kingdom of Saudi Arabia. Int J Pediatr Adolesc Med. 2017;4(2):61-5. doi: 10.1016/j.ijpam.2016.12.005. [PubMed: 30805503]. [PubMed Central: PMC6372492].

5. Juvonen J, Espinoza G, Schacter HL. Encyclopedia of mental health. 2nd ed. Massachusetts, USA: Academic Press; 2016

6. Vaillancourt T, Trinh V, McDougall P, Duku E, Cunningham L, Cunningham $\mathrm{C}$, et al. Optimizing population screening of bullying in school-aged children. J Sch Violence. 2010;9(3):233-50. doi: 10.1080/15388220.2010.483182.

7. Aliverdinia A, Sohrabi M. [Social explanation of school bullying (a case study on Sari city's high school students)]. Quarterly Journal of SocioCultural Development Studies. 2015;4(1):9-39. Persian.
8. Garmaroudi G, Mohammad K, Omidvari S, Jafarpour S. Prevalence of bullying and its associated factors among iranian middle school students. Health Education and Health Promotion. 2014;2(3):9-20.

9. Sadinejad M, Bahreynian M, Motlagh ME, Qorbani M, Movahhed M, Ardalan G, et al. Frequency of aggressive behaviors in a nationally representative sample of Iranian children and adolescents: The CASPIAN-IV study. Int J Prev Med. 2015;6:6. doi: 10.4103/20087802.151436. [PubMed: 25789141]. [PubMed Central: PMC4362279].

10. Chan HCO, Wong DSW. The overlap between school bullying perpetration and victimization: Assessing the psychological, familial, and school factors of Chinese adolescents in Hong Kong. J Child Fam Stud. 2015;24(11):3224-34. doi: 10.1007/s10826-015-0125-7.

11. Chui WH, Chan HC. Association between self-control and school bullying behaviors among Macanese adolescents. Child Abuse Negl. 2013;37(4):237-42. doi: 10.1016/j.chiabu.2012.12.003. [PubMed: 23313077].

12. Cook CR, Williams KR, Guerra NG, Kim TE, Sadek S. Predictors of bullying and victimization in childhood and adolescence: A metaanalytic investigation. School Psychology Quarterly. 2010;25(2):65-83. doi: 10.1037/a0020149.

13. Gini G, Pozzoli T. Bullied children and psychosomatic problems: A meta-analysis. Pediatrics. 2013;132(4):720-9. doi: 10.1542/peds.2013 0614. [PubMed: 24043275].

14. Klomek AB, Sourander A, Kumpulainen K, Piha J, Tamminen T, Moilanen I, et al. Childhood bullying as a risk for later depression and suicidal ideation among Finnish males. J Affect Disord. 2008;109(1-2):47-55. doi:10.1016/j.jad.2007.12.226. [PubMed: 18221788].

15. Karch DL, Logan J, McDaniel DD, Floyd CF, Vagi KJ. Precipitating circumstances of suicide among youth aged 10-17 years by sex: Data from the National Violent Death Reporting System, 16 states, 2005-2008. J Adolesc Health. 2013;53(1 Suppl):S51-3. doi: 10.1016/j.jadohealth.2012.06.028. [PubMed: 23790202].

16. Loveland JM, Lounsbury JW, Welsh D, Buboltz WC. The validity of physical aggression in predicting adolescent academic performance. Br J Educ Psychol. 2007;77(Pt 1):167-76. doi: 10.1348/000709905X79563. [PubMed: 17411493].

17. Holt MK, Finkelhor D, Kantor GK. Multiple victimization experiences of urban elementary school students: Associations with psychosocial functioning and academic performance. Child Abuse Negl. 2007;31(5):503-15. doi: 10.1016/j.chiabu.2006.12.006. [PubMed: 17537507].

18. Motlagh ME, Ziaodini H, Qorbani M, Taheri M, Aminaei T, Goodarzi A, et al. Methodology and early findings of the fifth survey of childhood and adolescence surveillance and prevention of adult noncommunicable disease: The CASPIAN-V study. Int I Prev Med. 2017;8:4 doi: 10.4103/2008-7802.198915. [PubMed: 28217266]. [PubMed Central: PMC5288959].

19. Lasserre AM, Viswanathan B, Bovet P. Global school-based student health survey. Geneva, Switzerland: World Health Organization; 2008. Available from: https://www.who.int/teams/noncommunicablediseases/surveillance/systems-tools/global-school-based-studenthealth-survey.

20. Zakeri M, Sedaghat M, Motlagh ME, Tayari Ashtiani R, Ardalan G. BMI correlation with psychiatric problems among 10-18 years Iranian students. Acta Med Iran. 2012;50(3):177-84. [PubMed: 22418986].

21. Heshmat R, Qorbani M, Ghoreshi B, Djalalinia S, Tabatabaie OR, Safiri $S$, et al. Association of socioeconomic status with psychiatric problems and violent behaviours in a nationally representative sample of Iranian children and adolescents: the CASPIAN-IV study. BMJ Open. 2016;6(8). e011615. doi: 10.1136/bmjopen-2016-011615. [PubMed: 27531729]. [PubMed Central: PMC5013516].

22. Poursafa P, Mansourian M, Motlagh ME, Ardalan G, Kelishadi R. Is air quality index associated with cardiometabolic risk factors in adolescents? The CASPIAN-III study. Environ Res. 2014;134:105-9. doi: 10.1016/j.envres.2014.07.010. [PubMed: 25127520]. 
23. Zahedi H, Kelishadi R, Heshmat R, Motlagh ME, Ranjbar SH, Ardalan $\mathrm{G}$, et al. Association between junk food consumption and mental health in a national sample of Iranian children and adolescents: The CASPIAN-IV study. Nutrition. 2014;30(11-12):1391-7. doi: 10.1016/j.nut.2014.04.014. [PubMed: 25280418].

24. Moore SE, Norman RE, Suetani S, Thomas HJ, Sly PD, Scott JG. Consequences of bullying victimization in childhood and adolescence: A systematic review and meta-analysis. World J Psychiatry. 2017;7(1):6076. doi: 10.5498/wjp.v7.i1.60. [PubMed: 28401049]. [PubMed Central: PMC5371173].

25. Steyn GM, Singh GD. Managing bullying in South African secondary schools: A case study. Int J Educ Manag. 2018;32(6):1029-40. doi 10.1108/ijem-09-2017-0248.

26. Kim YK, Okumu M, Small E, Nikolova SP, Mengo C. The association between school bullying victimization and substance use among adolescents in Malawi: The mediating effect of loneliness. Int J Adolesc Med Health. 2018;32(5). doi: 10.1515/ijamh-2017-0229. [PubMed: 29894300].

27. Tippett N, Wolke D. Socioeconomic status and bullying: A meta-analysis. Am J Public Health. 2014;104(6):e48-59. doi: 10.2105/AJPH.2014.301960. [PubMed: 24825231]. [PubMed Central: PMC4061998].

28. Healy KL, Sanders MR, Iyer A. Parenting practices, children's peer relationships and being bullied at school. J Child Fam Stud. 2013;24(1):12740. doi: 10.1007/s10826-013-9820-4.

29. Kim JW, Lee K, Lee YS, Han DH, Min KJ, Song SH, et al. Factors associated with group bullying and psychopathology in elementary school students using child-welfare facilities. Neuropsychiatr Dis Treat. 2015;11:991-8. doi: 10.2147/NDT.S76105. [PubMed: 25897236]. [PubMed Central: PMC4397930]. 